\title{
La estrategia digital de internacionalización de Marca en Latinoamérica. Estudio de caso de MARCA Claro en México
}

\section{The digital strategy of internationalisation of Marca in Latin America. Study case of MARCA Claro in Mexico}

\author{
José Luis Rojas Torrijos \\ Recibido: 26-08-2017 - Aceptado: 12-12-2017 \\ DOI: https://doi.org/10.26441/RC17.1-2018-A7
}

\begin{abstract}
RESUMEN: El presente artículo constituye un estudio amplio y detallado tanto del plan de contenidos y de la estrategia digital desarrollada en la web, la app móvil y en redes sociales para el lanzamiento en México en 2017 de MarcaClaro.com, nueva plataforma multimedia con la que el diario deportivo español Marca busca internacionalizarse y consolidarse como medio deportivo líder en el mercado iberoamericano. Para ello, se realiza un análisis de contenido de las piezas (jerarquización temática por deportes y competiciones, así como nuevos formatos y narrativas) publicadas en la web en sus primeros cinco meses de vida (enero y mayo de 2017), todas seleccionadas a partir de una muestra aleatoria, y entrevistas en profundidad a los responsables de MARCA Claro, tanto en España como en México, con el fin de conocer cuáles son los objetivos editoriales de esta alianza mediática transnacional.
\end{abstract}

Palabras clave: periodismo deportivo; periodismo digital; innovación; internacionalización; MARCA Claro; estrategia digital.

ABTRACT: This article is a thorough analysis of the content plan and digital strategy developed on the web, mobile app and social media for the launching in Mexico in 2017 of MarcaClaro.com, a new multimedia platform created by the sports daily newspaper Marca in order to internationalise and consolidate as a leading sports outlet in Latin America. For that purpose, first there is a content analysis of pieces of information (priorisation of topics and events, new formats and storytelling) published on the web during its first five months of life and selected through a random simple and, secondly, there are in-depth interviews to MARCA Claro chief editors both in Spain and in Mexico so as to know editorial keys of this transnational media partnership.

Key words: sports journalism; digital journalism; innovation; internationalization; MARCA Claro; digital strategy.

José Luis Rojas Torrijos es periodista con amplia experiencia en gabinetes de comunicación y medios radiofónicos, impresos y digitales. Es Doctor en Periodismo por la Universidad de Sevilla y Profesor Asociado del Departamento de Periodismo II de la misma universidad. Líneas de investigación: periodismo deportivo, periodismo especializado, innovación en periodismo, ética periodística, uso del lenguaje y libros de estilo. jlrojas@ us.es, http://orcid.org/0000-0002-7390-9843 


\section{Introducción: la innovación en un medio deportivo líder}

Los contenidos deportivos desempeñan como manifestación de la cultura contemporánea un papel estratégico en la actual estructura de los medios de comunicación (Miller, 2001; Rowe, 2003; Boyle, 2006) al tratarse de una temática que despierta el interés de audiencias millonarias y que, por tanto, sigue actuando como reclamo para anunciantes y patrocinadores, y moviendo cifras astronómicas en torno a la puja de los derechos de emisión de los grandes eventos deportivos cada temporada (Fujak, Frawley y Bush, 2017).

En unos momentos de complejidad en el nuevo ecosistema mediático, donde muchos medios tradicionales aún no han hallado un fácil acomodo en el Digital First y donde la irrupción incesante de nuevos emprendimientos periodísticos y nuevos dispositivos y canales han acabado por fragmentar cada vez más las audiencias (Túñez, 2010), el deporte se constituye como un elemento diferenciador de las parrillas de programación y como un pilar del negocio en torno al cual se realizan grandes inversiones que persiguen mejorar la cuenta de resultados de las empresas periodísticas. La sostenibilidad económica es a día de hoy una prioridad para ellas.

\subsection{Liderazgo nacional y potenciali- dad en el mercado de habla hispana}

Los distintos estudios de medición de las audiencias en España no dejan lugar a dudas y todos coinciden al subrayar el rango preeminente de los medios y espacios deportivos en el contexto de la oferta mediática actual. Así, el Estudio General de Medios (EGM) en su oleada de abril 2016-marzo $2017^{2}$ recoge que entre los diez diarios impresos más leídos cuatro son deportivos, cuya suma supera los cuatro millones de lectores diarios (Marca es líder nacional con más de dos millones), la radio temática deportiva (Radio Marca) se ha estabilizado en torno al medio millón de oyentes al día y los programas deportivos siguen siendo líderes en la franja de medianoche y en los fines de semana.

Además, según el informe 'Análisis Televisivo Año 2016’3, que elabora anualmente la empresa consultora Barlovento Comunicación, continúa la recuperación de la inversión publicitaria a la vez que la televisión de pago registra récord de consumo (casi 5,85 millones de suscriptores y más minutos de visionado que espectadores tradicionales), merced a la competencia de las empresas de telefonía y las empresas de streaming apuestan por el mercado español.

Todos estos datos confluyen en el auge de los contenidos deportivos: las 39 emisiones más vistas de 2016 fueron retransmisiones deportivas, las operadoras de pago son competitivas en la medida en que tienen los derechos para ofertar acontecimientos deportivos y

\footnotetext{
2 http://www.aimc.es/-Datos-EGM-Resumen-General-.html

3 https://www.barloventocomunicacion.es/blog/147-analisis-televisivo-2016.html
} 
canales temáticos como Bein Sports o Movistar Fútbol son de los más seguidos, y las posibilidades de la emisión en directo a través de las nuevas plataformas están encontrando también en el deporte opciones para abrirse camino en el mercado.

Como ya se ha señalado, en este contexto de pujanza de los contenidos informativos sobre deporte, Marca es un medio líder, no solo en lo que respecta a los soportes de papel y radio tradicionales, sino también en la web. Así, marca.com es el primer sitio especializado en deportes en España con 4.519.000 usuarios únicos al mes, más del doble de su más inmediato perseguidor, $A s$, con 2.268.000, según indica el EGM digital febrero-marzo de 2017.

Imagen 1. Gráfico de barras del EGM digital febrero-marzo de 2017.

\section{SITIOS DE INTERNET*}

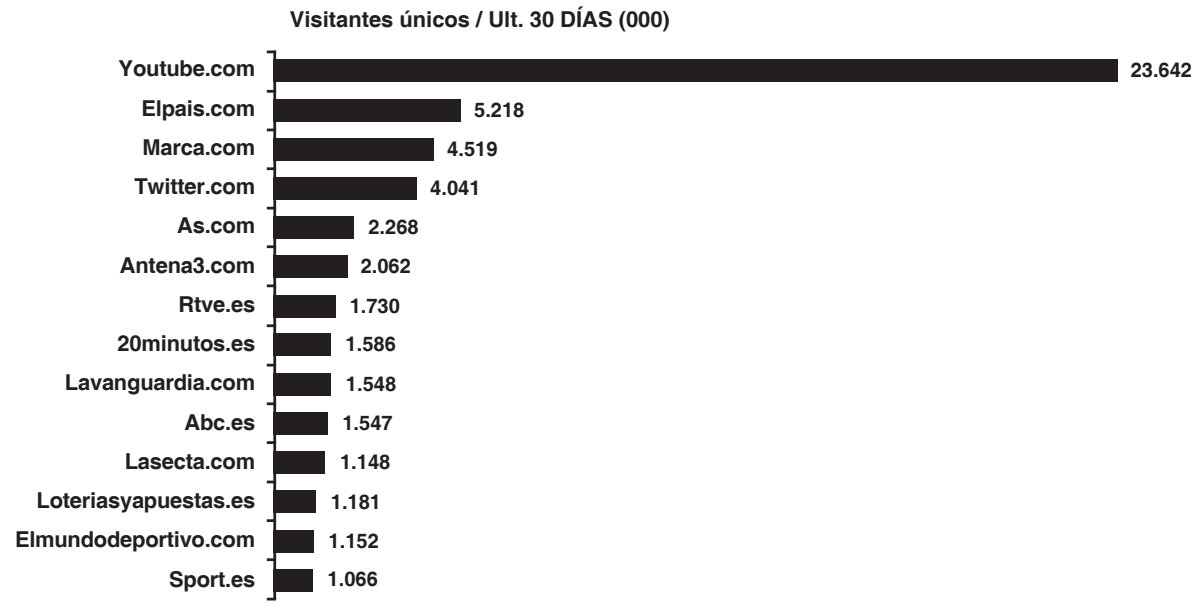

Fuente: AIMC.

En otro sistema de medición, el que realiza ComScore, empresa de investigación de marketing en internet que estudia el comportamiento online de los usuarios en la suma de plataformas (PC + móviles), marca.com también copa el primer lugar entre los medios digitales deportivos en España al situarse en mayo de 2017 con 13,1 millones de usuarios únicos diarios, 2.407.000 más que As y 4.896.000 más que Mundo Deportivo. 
Imagen 2. Tabla con los datos de ComScore de diarios deportivos en España.

Mayo 2017.

\begin{tabular}{|l|r|r|r|r|r|r|r|r|r|}
\hline \multirow{2}{*}{\multicolumn{1}{c|}{ DEPORTIVOS }} & \multicolumn{2}{c|}{ Total Digital Population } & \multicolumn{3}{c|}{ Desktop } & \multicolumn{3}{c|}{ Mobile } \\
\cline { 2 - 11 } & may-17 & vs mes-1 & vs año-1 & may-2017 & vs mes-1 & ves año-1 & may-2017 & vs mes-1 & vs año-1 \\
\hline $\begin{array}{l}\text { Total Internet: Total } \\
\text { Audience }\end{array}$ & 32.363 & -1 & 4 & 22.011 & -1 & -3 & 27.093 & 1 & 6 \\
\hline MARCA.COM & 13.169 & 1 & 11 & 4.275 & 3 & -11 & 10245 & 2 & 11 \\
\hline AS.COM & 10.762 & 1 & 21 & 3.640 & 8 & 10 & 8.196 & 0 & 22 \\
\hline MUNDODEPORTIVO.COM & 8.273 & 4 & 38 & 1.762 & 3 & -5 & 6.958 & 4 & 49 \\
\hline SPORT.ES & 5.104 & 1 & 19 & 1.359 & -4 & -7 & 4.026 & 3 & 27 \\
\hline
\end{tabular}

Fuente: ComScore.

Este liderazgo nacional, que sitúa a Marca como el equivalente en España de La Gazzetta dello Sport en Italia (Brunner y Horky, 2017), se ha mantenido en los últimos tiempos respecto a la competencia, pero, paradójicamente, se ha topado con una importante limitación para agrandarse: el centrarse principalmente en el mercado nacional. Cada vez resulta más complicado en España captar nuevos usuarios debido a la reducción de su tamaño y a la fragmentación progresiva de las audiencias en un ecosistema digital en el que cada vez operan más competidores. Por ello, y con el fin de expandir ese liderazgo y hallar nuevas audiencias aprovechando además la universalidad del idioma español, la internacionalización del producto Marca ha sido y es la gran apuesta de este medio deportivo para sumar nuevos públicos y seguir creciendo.

La necesidad de internacionalizarse para llegar a más audiencias en un mercado global de la información es un hecho que ha sido constatado ya por varios medios como el británico The Guardian, que abrió redacciones en Estados Unidos (2011) y Australia
(2013); Al Jazeera, la televisión de Qatar que además de su canal en árabe, tiene otro en inglés con sede en Londres desde 2006; $E S P N$ que ya cuenta con un sitio específico para lndia desde 2016; o incluso empresas periodísticas españolas como El País, con redacciones en Brasil y México, o el deportivo As, que también apostó por internacionalizarse hace unos años formando equipos de trabajo en países como Chile (2014), Colombia, México (2015) o Estados Unidos (2016).

Por tanto, la apuesta por la internacionalización de Marca se sitúa en un contexto en el que las empresas periodísticas tratan de expandir su producto y su sello informativo más allá de sus fronteras como parte de una estrategia de negocio muy clara. Esta búsqueda de la transnacionalidad se enmarca a su vez en un plan de acción integral en el que las principales empresas periodísticas, muy especialmente los legacy media (medios tradicionales), están ajustando su estructura, sus rutinas y procesos de producción a los cambios de los hábitos de consumo de las noticias en el 
mercado global y a la evolución de la tecnología digital y a sus posibilidades de aplicación para reformular las maneras de contar y presentar las historias al público, muy especialmente al más joven (Casero Ripollés, 2012).

\subsection{La nueva estrategia digital de Marca}

El proceso de internacionalización del medio deportivo Marca forma parte, por tanto, de una nueva estrategia empresarial que tiene como prioridad avanzar en lo digital, sin que ello signifique renunciar al producto impreso, que aún cuenta con una importante base de compradores y lectores en el mercado nacional.

Esa nueva estrategia digital de Marca que a continuación explicaremos tiene que ver directamente con la llegada en agosto de 2016 de Urbano Cairo a la presidencia y al puesto de consejero delegado de RCS, grupo italiano matriz de Unidad Editorial, al que pertenecen tanto este periódico deportivo como $\mathrm{El}$ Mundo o el económico Expansión en España, y que aglutina a medios tan importantes como el Corriere della Sera y la Gazzetta dello Sport en el país transalpino.

El nuevo dueño de Marca, propietario del grupo multimedia Cairo Communication ${ }^{4}$, afirmó nada más tomar posesión de su cargo que el grupo se encuentra "en un proceso de transi- ción" y mostró su compromiso de mejorar su proyecto de integración entre su grupo y el grupo editor de Marca "con el objetivo de acelerar la reestructuración operativa de RCS, beneficiándose de posibles sinergias de cara a conseguir aumentar los ingresos". Cairo también incidió en la importancia de aprovechar la internacionalidad de su grupo para beneficiarse "de las oportunidades derivadas de la fusión de los medios tradicionales con las plataformas digitales"

Por tanto, Marca afronta un proceso de cambio y adaptación a una nueva estrategia empresarial, la cual tiene como eje de actuación la búsqueda de sinergias entre medios socios y la producción multiplataforma (Marca en papel, el sitio marca.com, Radio Marca y productos específicos como Marca Plus, la revista quincenal interactiva para tabletas y smartphones en España nacida en 2014). Emergen aquí procesos de reestructuración y revisión en la organización de la redacción, a través de la asignación de nuevas tareas y de la identificación de perfiles profesionales que mejor hayan de ajustarse a los nuevos requerimientos de la demanda.

Entre esos nuevos requerimientos de la demanda está el profundizar en nuevas narrativas, formatos y estrategias de distribución de contenidos para con el fin de llegar más y mejor a los diferentes públicos y aumentar aún más la comunidad Marca. Uno de esos

\footnotetext{
4 Grupo de comunicación italiano al que pertenecen decenas de revistas y las cadenas de televisión La7 y del Torino FC.

5 http://www.marca.com/mundo-marca/2016/08/03/57a240cf22601d2a0c8b4647.html
} 
requerimientos es trabajar en la información pensando en la movilidad de la audiencia, esto es, en concebir las piezas para que en primer lugar sean consumidas en pequeñas pantallas de los dispositivos móviles, servírsela allí dónde esté y en cualquier momento.

Es tendencia global, y también particular dentro de Marca, que la proporción de usuarios que acceden a las noticias sea cada vez mayor a través de tabletas y smartphones antes que por ordenadores personales (PC). En Marca, a principios de 2017, los usuarios móviles ya superan el $70 \%$ del total, sumando aquellos que lo hacen a través de la web móvil y quienes lo hacen a través de la $a p p$ (en fines de semana de competición y durante el verano de 2016 el tráfico móvil llegó a picos que alcanzaron el $80 \%$ ).

Otro eje de actuación es aumentar el número de plataformas para distribuir los contenidos con los que llegar a unos usuarios que tienen un comportamiento en permanente cambio: no solo está en función de la época del año (si hay competición o no), sino sobre todo por la manera en que acceden a la información. Son cada vez más lo que llegan a ella o buscándola (buscadores como Google) o encontrándosela en redes sociales y otros canales como newsletters, alertas o apps de mensajería como Whatsapp o Telegram.

Teniendo en cuenta que, pese a ser una marca periodística fuerte y reconocida mundialmente, cada vez es menor el tráfico directo a la web (cada vez menos usuarios teclean www.marca. com,) y el público más joven vive en las redes sociales, otro de los objetivos de la estrategia digital de Marca es aprovechar las posibilidades de las nuevas plataformas para conectar directamente con la audiencia y llegar a nuevos públicos. De esta forma, persigue desarrollar una creatividad propia ahí para presentar los contenidos de forma original, atractiva y específica según las características de cada red social.

La nueva estrategia digital de Marca, además de ampliar fronteras, apostar por las nuevas narrativas, potenciar las posibilidades multiplataforma, pensar primero en lo móvil y desarrollar una nueva estrategia de distribución a través de las plataformas sociales, pasa por la innovación como receta clave para procurar el crecimiento. La innovación aparece, así, como fórmula para cambiar y dar con las soluciones que mejor se presten en cada temática, contenido o formato con el fin último de satisfacer y fidelizar a cada tipo de público.

Los nuevos requerimientos del mercado pasan así por inculcar en el conjunto de la redacción una cultura de la innovación, un concepto transversal que afecta a todos los órdenes de la actividad de las organizaciones de noticias, de forma que esta vaya calando y se plasme en la producción de unos contenidos periodísticos que sean actuales, diferenciadores y de calidad.

\subsection{Bases para la creación de un Marca Lab}

Esa apuesta decidida por la innovación periodística tuvo como consecuencia la creación en agosto de 2015 
de una pequeña unidad de trabajo empresa-Universidad a partir de la cual comenzar a crear nuevos formatos y mejorar el producto periodístico digital y móvil de Marca. Desde entonces este medio deportivo cuenta con un servicio de consultoría en innovación digital y calidad que ofrece el profesor e investigador de la Universidad de Sevilla José Luis Rojas Torrijos. La idea inicial de este proyecto es sentar las bases para la constitución de un futuro Marca Lab o laboratorio de innovación periodística, con el que ya cuentan diversos medios españoles como el grupo Vocento, El Confidencial o el Diario de Navarra.

Desde este servicio de consultoría se viene realizando desde la fecha señalada un seguimiento y análisis semanal de las últimas tendencias tecnológicas, narrativas y de producto que se desarrollan en el ámbito del periodismo deportivo, tanto nacional como internacional, para la evaluación de contenidos y posterior propuesta de posible aplicación de ideas para la web y otros productos digitales de Marca.

Se efectúa un estudio amplio y actualizado de las innovaciones que acometen los medios de comunicación tanto generalistas como exclusivamente deportivos y que sean referentes en este ámbito (los modelos más seguidos en este sentido son The New York Times,
The Washington Post y The Guardian, por un lado; y L'Équipe, La Gazzetta dello Sport, Sports Illustrated y Bleacher Report, por otro), así como de las investigaciones académicas más relevantes que se realicen y publiquen en revistas científicas y foros relacionados con el periodismo, cuyos resultados y conclusiones sean aprovechables y transferibles (estudios, por ejemplo, como los que realiza el centro Pew Research en Estados Unidos o el Reuters Institute for the Study of Journalism de la Universidad de Oxford en el Reino Unido).

Esta labor de seguimiento y evaluación incluye también el testeo de cada una de las novedades que se introduzcan en el entorno digital y móvil de Marca con el objetivo de validar sus resultados a través de reuniones periódicas tanto presenciales en Madrid como de carácter virtual en las que toman parte las personas responsables tanto de la dirección y subdirección del medio como de las área de Infografía, Redes Sociales, Estrategia Digital o Fotografía y Vídeo. En esos foros de encuentro, de periodicidad trimestral, todos los profesionales implicados aportan sugerencias y debaten pros y contras de soluciones planteadas o probadas. De esta forma, la puesta en común de ideas sirve también para evaluar los resultados de la innovación acometida. 
Imagen 3. El rediseño de la portada nueva (izda.) y el de la antigua (dcha.) de Marca.com
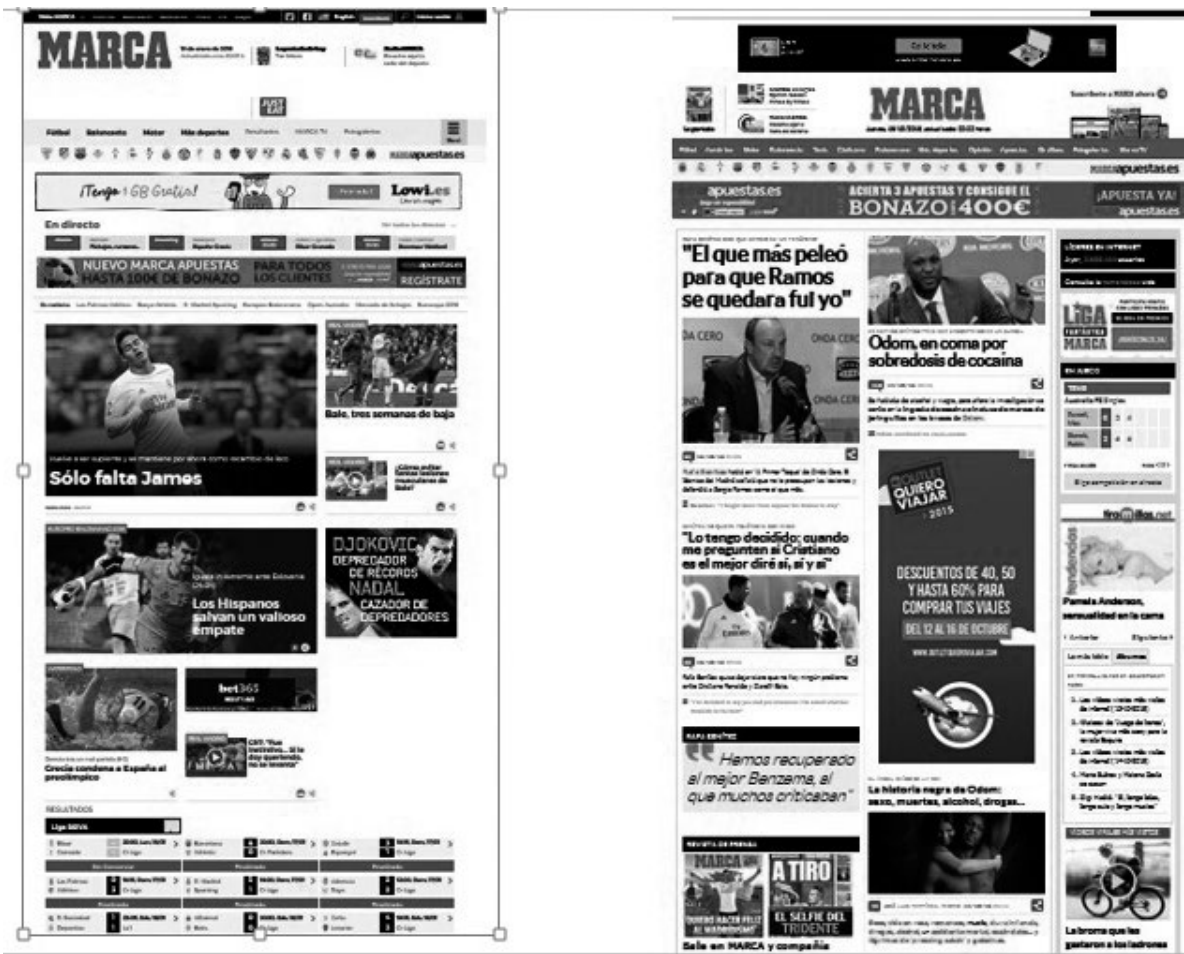

Entre las mejoras introducidas en marca.com en estos dos últimos años figuran las siguientes:

- Rediseño web

Se ha avanzado hacia un diseño más limpio de la web con una distribución racional de la información y un mayor peso visual de los temas del día (imágenes, fotogalerías, vídeos y streaming de competiciones), al mismo tiempo que se han mejorado algunas cuestiones como la jerarquización de los contenidos noticiosos, una mayor visibilidad de resultados con clasificación, datos de la jornada y directos; se ha aminorado la longitud del scroll teniendo en cuenta la tendencia a que los usuarios entren cada vez más desde la app y redes sociales; y se ha aumentado el número de hiperenlaces y noticias relacionadas con el fin de agrupar y contextualizar mejor la información.

- Cobertura en directo de eventos

Se han enriquecido los directos, con más datos, interacción, apoyos gráficos, con el fin de potenciar el formato que más tráfico lleva a la web. Actualmente se hacen en torno a 80 a la semana, junto con unos 20 streams de eventos. Es una de las grandes apuestas de marca. 
com y se sigue trabajando en su mejora, tanto en el diseño como en las funcionalidades para dispositivos móviles.

- Infografía y periodismo de datos

Por otra parte, se ha seguido potenciando el peso infográfico de las noticias, con especiales, informes e interactivos, y se avanza hacia el periodismo de datos a partir del análisis con gráficos. En esta línea, se han hecho previas con datos clave de la jornada, partido a partido, para ayudar al lector a seguir la nueva jornada liguera; o historias en clave numérica como una manera ágil sin recurrir a gráficos de contar la historia y de hacerla más atractiva y legible. Se persigue así por un lado, avanzar hacia una línea de información de servicio que ofrezca al mismo tiempo muchos datos y que estos sean fácilmente digeribles, y, por otro, aprovechar el potencial estadístico que se genera en el deporte para hacer un mejor periodismo de datos, de forma que este se visualice en gráficos y en un peso cada vez mayor de los datos en los textos informativos.

Imagen 4. Gráfico interactivo del reportaje "Rayo Nacho"6

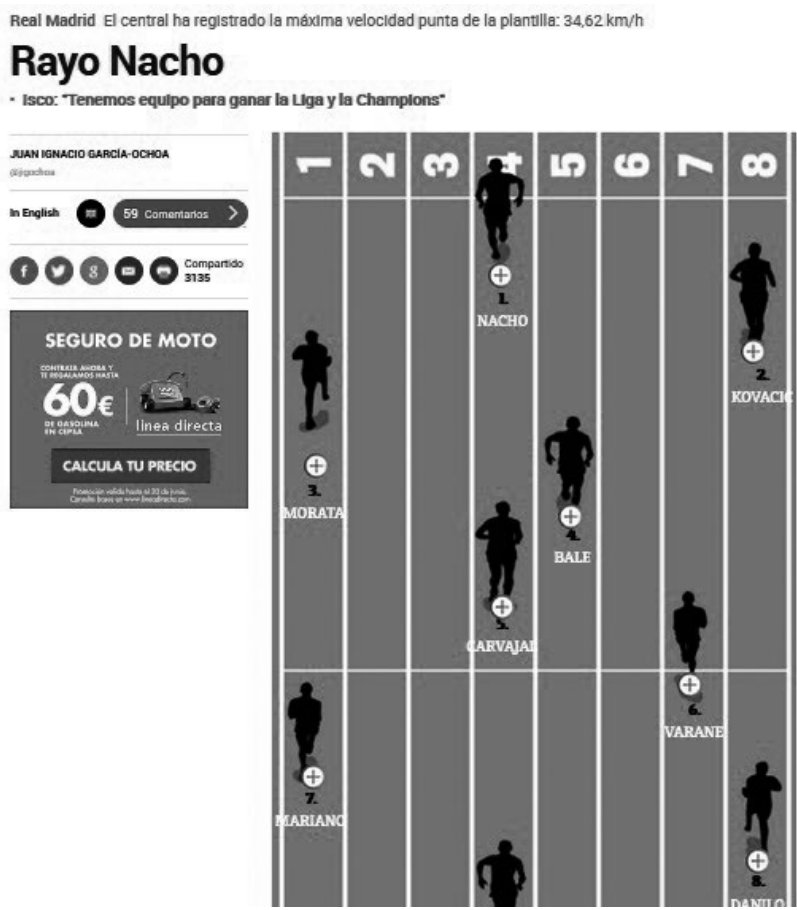

Fuente: marca.com

6 http://www.marca.com/futbol/real-madrid/2017/03/31/58dd59d0e5fdea68768b45e3.html 
- Nuevos formatos visuales

La apuesta por las nuevas narrativas digitales en Marca reside en un alto porcentaje en resaltar el peso visual de la información con vídeos, gráficos y fotografías mediante nuevas formas de contar. Aquí es importante reseñar la importancia adquirida por el vídeo como eje del engagement al ser un formato cada vez más demandado tanto en la web como sobre todo desde las apps móviles.

En Marca los vídeos alcanzan una media de entre 35 y 43 millones de visualizaciones al mes ${ }^{7}$, la diferencia que va de los meses de verano (junio-julio) a los del desenlace de las competiciones en abril-mayo. De esa cantidad de visualizaciones, el 30\% corresponde a la app, donde Marca tiene una media de 2,1 millones de usuarios, los cuales consumen alrededor de 500 millones de páginas mensuales.

Teniendo en cuenta estos datos, se han creado interactivos multimedia con diversidad de elementos integrados (diseño, contenido propio elaborado, con infografía integrada y vídeos) o especiales videográficos que aprovechan la hemeroteca, un recurso por explotar para dar valor añadido o piezas que combinan la secuencialidad de lectura del scroll vertical con la horizontal.

Por otra parte, se ha avanzado en la gamificación de la información a través de software como PlayBuzz, Thinglink o Tableau y la introducción de elemen- tos interactivos que invitan al usuario a permanecer más tiempo en la página. De esta forma, los contenidos de la web marcan una distancia cada vez mayor respecto a los formatos tradicionales, más comunes en el soporte papel, como son las previas, las crónicas y las piezas declarativas.

A este respecto, cabe señalar el carácter pionero de Marca Plus en la experimentación de estas nuevas fórmulas narrativas, que tienden a aproximar al lector a la actualidad informativa de forma amena y, a la vez, procurarle una experiencia diferente de navegación entre la multitud de posibilidades interactivas que la publicación ofrece (Rojas Torrijos, 2015).

- Primera Plana y la apuesta transmedia

Marca lanzó en marzo de 2016 el suplemento Primera Plana, un cuadernillo que de forma gratuita aparece con la edición dominical del periódico y que contiene reportajes e historias en páginas especiales con el ánimo de ofrecer calidad y diferenciación. El suplemento en el papel también tiene continuidad en la web, donde cuenta con una sección propia y las piezas se enriquecen a partir de las posibilidades multimedia que ofrece el soporte digital, muy especialmente gráficos interactivos muy pertinentes y atractivos y vídeos.

Junto con estos avances, la estrategia digital de Marca ya tiene trazados varios pasos a seguir en el horizonte más

7 Fuente: documentos internos de Marca facilitados por su subdirector Emilio Contreras. 
cercano $^{8}$. Entre otros objetivos, se encuentran los de potenciar la información de servicio aumentando canales de distribución de contenidos con más notificaciones desde la $a p p$ y más segmentadas por temáticas (alertas con fútbol internacional, por deportes, equipos...), elaboración de diferentes tipos de newsletters y reforzar el uso de canales de mensajería (Whattsapp/Telegram/Messenger).
Otras líneas de actuación serán la mejora de la presencia de Marca en redes sociales, desarrollar nuevas funcionalidades en la $a p p$, crear espacios colaborativos dentro de la web para hacer más partícipes a los usuarios (como en la sección ProLiga/Más Fútbol) y, de manera muy especial, tejer alianzas para impulsar la expansión de Marca en el continente americano.

Imagen 5. Cabecera de la web MARCA Claro.

\section{MARCA Claró- \\ 11 de enero de 2017 Actualicado a tas $23.45 \mathrm{~h}$.}

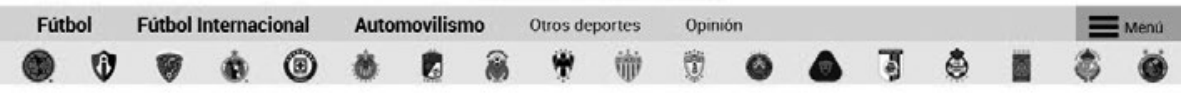

\section{Estudio de caso}

Tras la presentación y contextualización de la estrategia digital que desarrolla Marca, a continuación se presenta aquí un estudio en profundidad del plan de contenidos y de la estrategia digital desarrollada en la web, la $a p p$ móvil y en redes sociales para el lanzamiento en México en 2017 de MARCA Claro, nueva plataforma multimedia iberoamericana.

\subsection{Objetivos y metodología}

El objetivo prioritario de este artículo es reflexionar y conocer la situación de un medio deportivo líder en el nuevo entorno digital, así como sus claves y estrategias para adaptarse y crecer. A este respecto, cabe comprobar hasta qué punto la internacionalización se presenta como una solución en un momento de cambio de hábitos de consumo de la información entre la población y de reformulación en las maneras de presentar los contenidos a través de las nuevas plataformas globales de comunicación.

Para ello, tomando como objeto de estudio el proyecto MARCA Claro, que pilota el diario deportivo español en América Latina, esta investigación parte de un análisis de contenido de tipo cualitativo de las piezas publicadas en la web en sus primeros cinco meses de

8 Según información suministrada por el subdirector de Marca y principal responsable de la web de este diario, Emilio Contreras. 
vida (enero y mayo de 2017). La muestra del análisis, efectuada a partir de una selección fundamentada en los criterios de novedad introducidos en las piezas informativas en cuanto a formatos y temáticas tratadas, sirvió para categorizar y medir tanto el grado de innovación existente en las informaciones, los géneros predominantes, así como el número de modalidades deportivas abordadas. Con todo ello, el objetivo ha sido discernir cómo la nueva plataforma de información deportiva vuelca sus prioridades, tanto en lo que respecta a la jerarquización temática por deportes y competiciones, como en su apuesta por los nuevos formatos y las nuevas narrativas digitales.

En segundo término, se ha procedido a efectuar entrevistas en profundidad a los responsables de MARCA Claro, tanto en la redacción de España como en México, con el propósito de conocer cuáles son los objetivos editoriales de esta alianza mediática transnacional y los futuros pasos que se van a dar para expandir la iniciativa a otros países del arco latinoamericano. Las entrevistas se realizaron por conversación telefónica los días 27 y 28 de abril de 2017 .

\subsection{El proyecto MARCA Claro}

La internacionalización de Marca en América Latina constituye un paso clave de la estrategia digital de su grupo editor, el italiano RCS, para los próximos años. Tras más de un año de negociaciones, en enero de 2017 se puso en marcha la web marcaclaro.com. Esta iniciativa, fruto de la alianza entre el diario deportivo español y el canal de televisión mexicano Claro Sports (grupo Carso), propiedad del magnate Carlos Slim, supone el inicio de la expansión de Marca por todo el mercado latinoamericano para consagrarse como el medio líder en el ámbito del periodismo deportivo en lengua española.

México es, por su ubicación y dimensión (tiene 129 millones de habitantes, décimo país más poblado del mundo ${ }^{9}$ y es la segunda economía más grande de la región), la mejor puerta de entrada al mercado latinoamericano, incluyendo a la población hispana de Estados Unidos. De ahí que el proyecto haya comenzado por este país para, en sucesivas etapas, ir creciendo y llegando a otros mercados importantes de la zona como Colombia o Brasil.

\subsubsection{El potencial del mercado perio- dístico deportivo en México}

El periodismo deportivo se halla en plena expansión en Latinoamérica, es el más seguido en la mayor parte de los países y no deja de crecer en número de cabeceras, como en nuevos emprendimientos periodísticos (Breiner, 2013). Donde más han proliferado es precisamente en México, donde hay actualmente cuatro diario deportivos en papel (Récord, Esto, Estadio, Ovaciones) (Rojas Torrijos, 2011: 27); también está As México online, y donde el deporte tiene peso dentro de las secciones y

9 http://www.excelsior.com.mx/nacional/2017/06/21/1171150 
suplementos en los diarios generalistas. De estos últimos sobresalen La Afición (antiguo diario deportivo, hoy suplemento de Milenio) y Cancha (cuadernillo del prestigioso Reforma). Incluso destaca otro tipo de publicaciones no deportivas, que, sin embargo, han apostado desde siempre por contar con una relevante sección de Deportes: la revista política Proceso (periodismo de investigación en deportes) y El Economista (diario financiero, que muestra el deporte desde el punto de vista de la industria y el negocio).

Otro aspecto destacable es el nacimiento en Latinoamérica de nuevos medios deportivos digitales, emprendimientos periodísticos que surgen como alternativa a los medios tradicionales con nuevos enfoques y una apuesta por el periodismo narrativo, de largo aliento, y que están incorporando apuestas más creativas e innovadoras, que fundamentan su crecimiento en un modelo distributivo a través de las redes sociales. Entre esos nuevos deportivos digitales, destaca Juan Futbol (pronunciado así, como palabra aguda) en México.

El deporte se consume masivamente en México. Así se observa en todas las tipologías de medios, desde los más tradicionales hasta los nativos digitales. Según el informe Global Entertainment and Media Outlook 2015-2019 de Price Waterhouse Coopers ${ }^{10}$, el papel crece a diferencia de otros países de Latinoamérica y el resto del mundo. Así esta investigación señala que se prevé que el promedio de circulación diaria se incremente más rápido en México que en cualquier otro país en Latinoamérica, con una tasa de crecimiento anual compuesta de $3 \%$, llegando así casi a los 8 millones de ejemplares en 2019, frente a los 6,9 millones en 2014. Asimismo, indica que los ingresos totales de circulación están creciendo constantemente, impulsados por historias sensacionalistas en los diarios más leídos, y representará una parte cada vez mayor de los ingresos totales de la industria, llegando 1.870 millones de dólares en 2019.

El deporte vende en papel pero también en la web. Nuevos medios deportivos, de los más leídos también sobresalen hasta tres deportivos. Además del mencionado Juan Futbol y de Referee, el nativo digital de Deportes más seguido es Mediotiempo.com con una media de 2,3 millones de visitantes únicos mensuales, según el balance 2016 en comScore.

Por otra parte, en México se incrementa definitivamente el consumo de noticias por telefonía móvil. De hecho, por primera vez en este país, en 2016 el dispositivo desde el que más mexicanos se conectaron a internet fue el smartphone $(70 \%)$ y ocho de cada diez internautas lo utilizaron para acceder a sus redes sociales, según datos de la consultora Iab México ${ }^{11}$.

Todo hace apuntar pues que el deporte crece y que, cada vez más, los

\footnotetext{
10 http://www.pwc.com/mx/es/publicaciones/entertainment-and-media-outlook-mexico-2015-2019.html

11 http://eleconomista.com.mx/tecnociencia/2017/01/04/tendencias-medios-nativos-digitales
} 
ávidos consumidores de contenidos deportivos en México lo hacen a través de apps y webs móviles, así como de las redes sociales. Los informes consultados apuntan también a una demanda exponencialmente creciente de contenidos deportivos en vídeo y de contratación de servicios de streaming en plataformas digitales dejando un poco de lado a la televisión convencional.

Junto con todo ello, México se ha consolidado en los últimos años como una sede principal de grandes eventos deportivos internacionales. El nutrido calendario anual de competiciones deportivas en este país, más allá de la poderosa Liga de fútbol masculina y del nuevo campeonato de fútbol femenino, también da una idea de las potencialidades informativas que tiene el proyecto MARCA Claro.

A continuación, se presenta aquí un estudio amplio y detallado tanto del plan de contenidos preparado para el lanzamiento de esta nueva plataforma deportiva multimedia iberoamericana como de la estrategia digital desarrollada tanto en la web, la $a p p$ móvil como en redes sociales con vistas a su implantación este año. Para ello, se realiza un análisis de las piezas (jerarquización temática por deportes y competiciones, así como nuevos formatos y narrativas) publicadas en la web en sus primeros cinco meses de vida (enero-mayo de 2016), y entrevistas semiestructuradas a los responsables de MARCA Claro, tanto en España como en México, con el fin de conocer cuáles son los objetivos edito- riales de esta alianza mediática transnacional.

\subsubsection{Claves y potencialidades de esta alianza}

La alianza editorial MARCA Claro conjuga las potencialidades de dos medios: por un lado, la web del periódico deportivo más leído en España y, por otro, una televisión que tiene derechos de emisión de todo tipo (posee los de dos clubes de fútbol, Pachuca y León, y contaron con la exclusividad para emitir los JJ.OO. en Sochi y Río en toda Latinoamérica, excepto Brasil) y que, a su vez, es propiedad de América Móvil, compañía de telefonía móvil presente en 18 países del continente, con más de 260 millones de clientes, 54 de los cuales están en México.

El nuevo proyecto ha echado a andar desde las redacciones centrales de cada medio, en Madrid y Ciudad de México, y aspira a ir creciendo poco a poco, siguiendo un proceso de mejora gradual. Para ello, se ha formado un equipo inicial de unas once personas (además de redactores especializados en los principales equipos del país, hay infografistas, diseñadores, periodistas de datos y expertos en la gestión de redes sociales) que prevé ir haciéndose y ampliándose, y que está coordinado en Ciudad de México por el periodista Daniel Ancheyta.

Este equipo se encarga de elaborar alrededor del $30 \%$ de los contenidos, mientras que el resto se hace desde un equipo de periodistas que trabajan exclusivamente para esta nueva web desde la redacción de Marca en 
Madrid, todos ellos coordinados por Gerardo Riquelme, subdirector del periódico.

MARCA Claro pivota, además, sobre una doble estrategia claramente definida: la importancia de apostar por los contenidos internacionales, muy especialmente aquellos que estén relacionados con los deportistas mexicanos que compiten en las principales ligas europeas; $y$, por otra parte, la necesidad de avanzar y marcar diferencias en la información de carácter local o nacional.

Esta doble apuesta pasa también por salvar las diferencias culturales que existen entre España y México, también en el ámbito deportivo, así como de hábitos de consumo en ambos mercados. "Ya hemos estudiado al público mexicano y sabemos que Real Madrid y Barcelona son nuestros principales embajadores, son los que generan más atención; pero queremos llegar a aficionados mexicanos y esto pasa también por cubrir deportes que en España apenas existen como el béisbol, fútbol americano o lucha, que serán prioritarios. En todo caso, realizaremos un seguimiento al comportamiento de la audiencia mexicana para ir adaptando y mejorando cada vez más nuestros contenidos", explica el subdirector de Marca y máximo responsable de la web, Emilio Contreras.
El objetivo inicial es, según Contreras, "construir la web de información deportiva de referencia en México y que esta vaya más allá de una web-televisión, no solo subiendo vídeos (algo que ya está muy bien cubierto al ser Claro un canal consolidado), sino también apostando por las nuevas narrativas y los nuevos formatos digitales".

De hecho, el vídeo es uno de los pilares de esta alianza. Según datos recogidos por El Economista ${ }^{12}$ en México el 36\% de los usuarios tiene una cuenta de contenidos Over The Top (OTT), que permite ver contenidos por internet, y el segundo servicio más popular es precisamente Claro Video (el 35\% de los usuarios lo tienen), solo después de Netflix. Durante los Juegos Olímpicos de Río Claro despegó en este mercado al emitir 3.000 horas en directo y reproducir 240 millones de vídeos.

A partir de las potencialidades y la experiencia de cada medio, existe una importante coordinación editorial entre ambos equipos, y desde Madrid se ha asesorado, sobre todo en los meses previos al lanzamiento, sobre la importancia del lenguaje web y sobre la necesidad de preparar un plan de contenidos propios con el fin de marcar diferencias desde el principio respecto a los medios deportivos competidores en México.

12 http://eleconomista.com.mx/tecnociencia/2017/03/03/marca-claro-alianza-doble-contenido-triple-negocio 
Imagen 6. Ejemplo de nuevos formatos. Gráfico del reportaje informe "La altitud de la Ciudad de México también afecta a los equipos de la Liga MX"13.

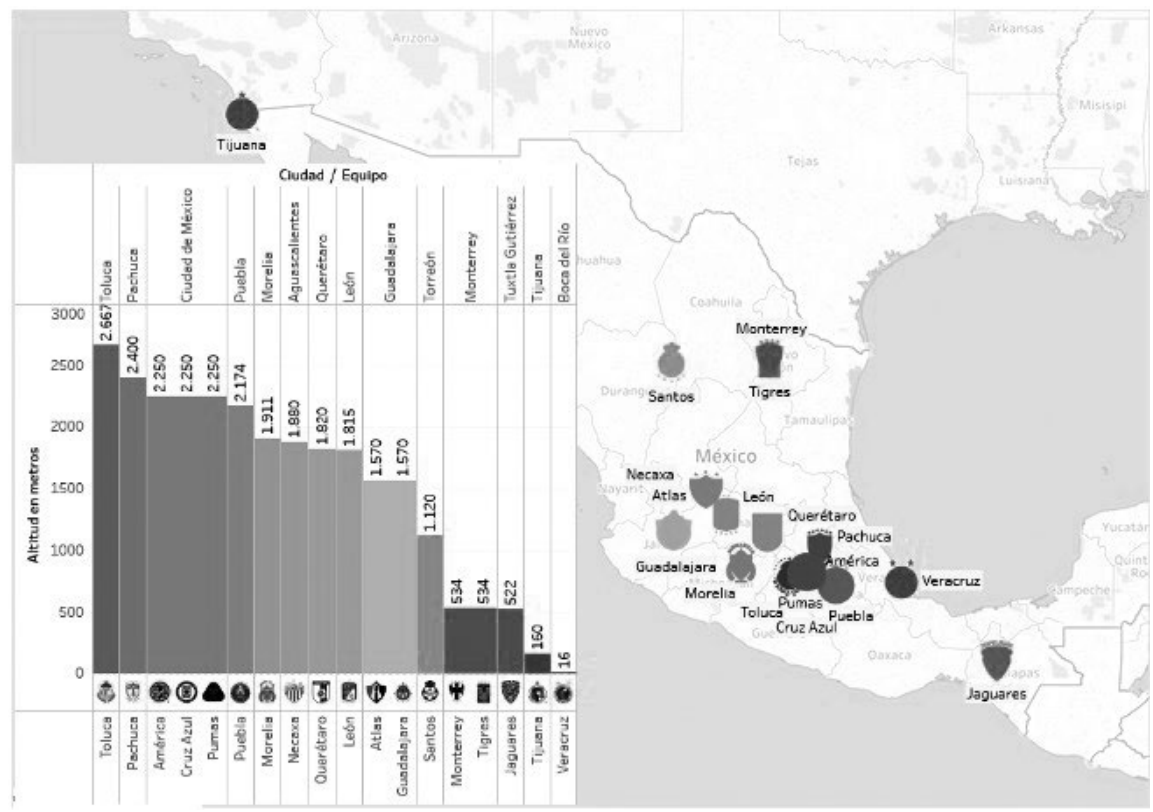

Fuente: MARCA Claro.

2.2.3. Prioridades editoriales: principales apuesta de contenidos, formatos y narrativas

A partir de esos objetivos ya señalados, el plan de contenidos presentado por MARCA Claro en estos primeros meses de andadura se ha fundamentado en las nuevas narrativas digitales dotando a los contenidos de mayor atractivo a la hora de presentar las historias.

Así, partiendo de una web donde los textos eran más bien escasos y rápidamente enlazaban a imágenes de vídeo, se ha apostado por la profundidad y el contexto a través de nuevos formatos como fotogalerías, gamificación, mayor participación (encuestas, debates, comentarios), periodismo de datos (infografías), e historias exclusivas y reportajes especiales conducidos por imágenes.

En lo que respecta a los contenidos, la baza prioritaria ha sido el fútbol local, esto es, informar del deporte más seguido como forma más rápida de atraer al gran público en un momento clave para

\footnotetext{
13 http://www.marca.com/claro-mx/futbol/liga-mx/2017/03/24/58d54d66e2704e3a2e8b45be.html
} 
darse a conocer y buscarse un sitio en el mercado como son los primeros meses de vida del proyecto. Esta apuesta por el fútbol mexicano hace especial incidencia no solo en la Liga MX sino también en los principales deportistas de este país por el mundo, de manera especial quienes compiten la Liga española pero también otros como Chicharito Hernández en la Bundesliga o Miguel Layún, Héctor Herrera y Jesús Manuel Corona en el Porto portugués.

Los directos son el formato que más demanda la audiencia en España, especialmente la que consume la información en el móvil, que, como señalábamos más arriba, llega ya al $70 \%$ en México. Por ello, los responsables de MARCA Claro consideran esta una prioridad y confían en que este formato pronto tenga en México el mismo éxito que ya ha demostrado en España. La apuesta por el minuto a minuto de acontecimientos en marcha no solo se ceñirá al fútbol sino también a otros deportes de gran seguimiento en este país norteamericano como, por ejemplo, la Fórmula Uno o el boxeo. En este sentido, la apuesta de MARCA Claro es incrementar el número de directos semanales.

A medida que vaya evolucionando el proyecto MARCA Claro, se aumentará la cobertura informativa del resto de deportes, incluyendo también el olimpismo, una temática sobre la que precisamente Claro Sports ha venido informando en los últimos años con gran dedicación en los ciclos previos a los Juegos de Sochi y Río, citas que emitió.

Otras líneas prioritarias de actua- ción para el futuro se centrarán en realizar un mayor trabajo de SEO para posicionar la web mejor en Google y Facebook, y en contar con experto en redes sociales para crear más contenidos específicos con los que llegar a más gente, muy especialmente la población más joven, usuaria habitual de los nuevos dispositivos.

Igualmente, está previsto realizar una mayor promoción de la $a p p$ pensando sobre todo el consumo de fin de semana (directos y resultados) y lanzar un SMS diario para impactar en un gran potencial audiencia (54 millones de clientes de América Móvil en México) con el contenido más relevante del día.

\section{Resultados y evaluación de sus res- ponsables}

En apenas cinco meses de andadura, MARCA Claro ha experimentado un crecimiento del 264\%, "lo que ayuda a pensar que se ha empezado bien un largo camino”, señala Gerardo Riquelme, coordinador de contenidos de la web en España.

Es digno de destacar el peso creciente de MARCA Claro en el balance de resultados de marca.com, al conseguir en abril y mayo de 2017 más de 4 millones de usuarios únicos y más de 23,6 millones de páginas vistas. Aunque parte lógicamente de cero (no hay métricas interanuales con las que compararse), teniendo en cuenta el volumen de visitas que llegan a marca.com de Latinoamérica (casi 11,5 millones de usuarios únicos, lo que supone un $23 \%$ del total), hay mucho potencial para crecer más en México. 
Imagen 7. Métricas obtenidas por el conjunto de webs de marca.com en abril de 2017

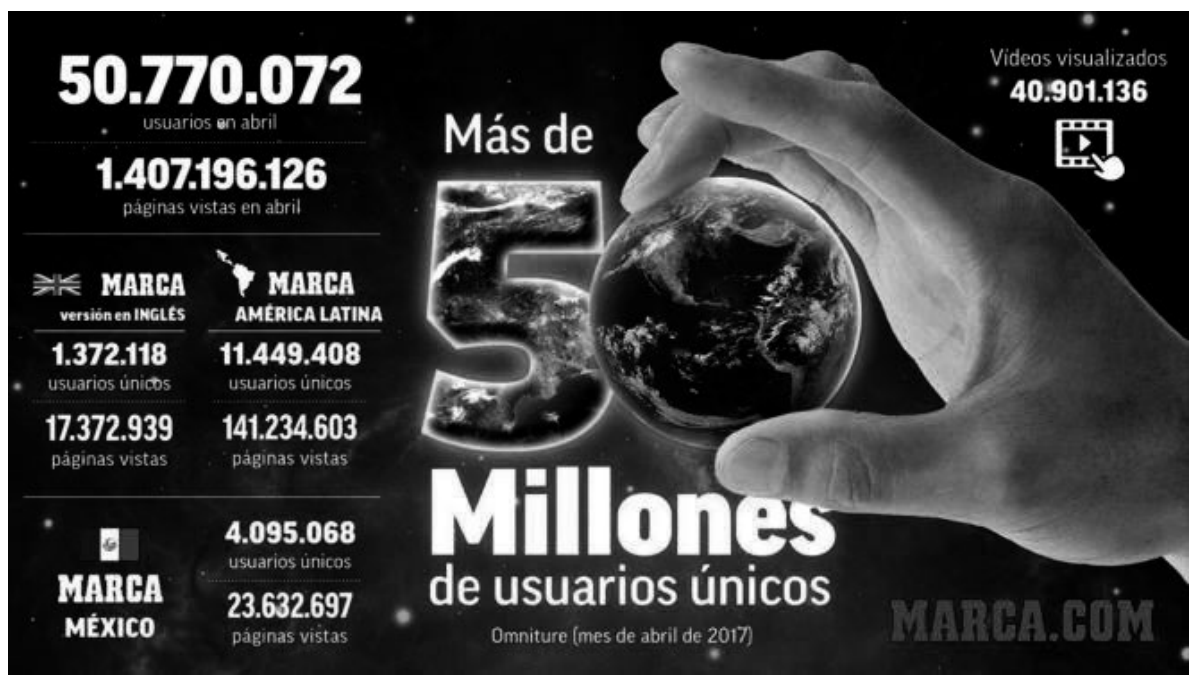

Fuente: Omniture/Marca.com.

Así, abril de 2017 fue un mes de ré- cifras de mayo de 2015- y logrando cord en la historia de la web de Marca 1.407.196.126 páginas vistas, también con 50.770.072 navegadores únicos la mayor cifra alcanzada nunca por -superando en más de medio millón las marca.com.

Imagen 8. Métricas de Marca.com en 2017
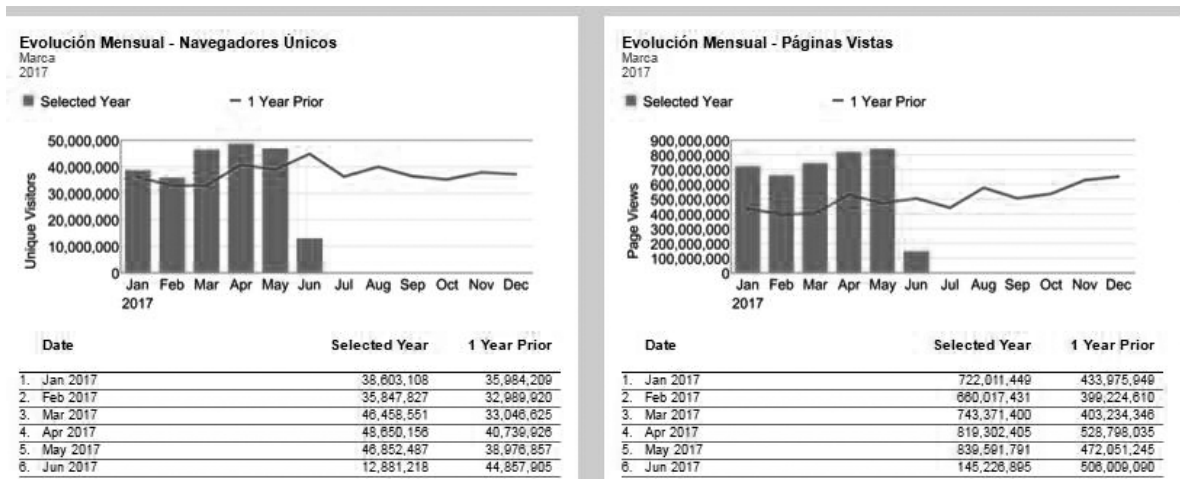

Fuente: Marca. 
Además, los notorios resultados alcanzados hasta ahora por MARCA Claro se han notado en las métricas de la suma del conjunto de los sitios de Marca. Como se ve la Imagen 8, en los primeros meses de 2017 marca.com ha crecido una media del $17 \%$ en navegadores únicos y un $45 \%$ en páginas vistas.

Los primeros meses del proyecto han sido evaluados de forma muy positiva por los dos coordinadores de contenidos de la plataforma. Así, Daniel Ancheyta desde México señala que "la coordinación con España ha sido en general muy buena" y agrega: "Ellos han tenido una gran actitud y una gran disposición para que las cosas fluyan de la mejor forma posible. Ayudaría mucho a nuestro crecimiento que nos compartieran un manual de estilo o de redes sociales".

A su juicio, la operación en México tiene mucho margen de crecimiento. "Los reporteros tienen más experiencia en televisión y poca en digital. Hemos tratado de imbuirles el chip digital (que generen una mayor cantidad de temas posibles y no nos quedemos con las conferencias de prensa) y de Marca, que es buscar la mayor cantidad de exclusivas a los personajes de peso en la Liga MX y en el deporte mexicano", indica Ancheyta, quien admite la necesidad de contar con más redactores para cubrir más y mejor la actualidad deportiva.

"Si bien hay aspectos que pulir, la redacción en México ha entendido a la perfección el flujo de trabajo de $M A R C A$ Claro, el manejo de portada, la línea editorial pese a las limitaciones de recursos humanos y técnicos. La redacción ha sido fundamental para el arranque del proyecto, los redactores han entendido que ya no son simples redactores, sino creadores de contenido".

Por su parte, Gerardo Riquelme coincide con Ancheyta al señalar que se trata de un proyecto periodístico de largo recorrido en el que los frutos deben de ir llegando poco a poco. "Lógicamente, nos enfrentamos a un camino que no es sencillo, que exige una coordinación diaria de múltiples departamentos (tecnología, marketing, redes sociales, dos redacciones con un modo de trabajar distinto en el pasado...) y que obliga a dar pasos más cortos, pero seguros".

Lo que el subdirector de Marca tiene claro es que para ir cumpliendo los objetivos trazados con esta alianza "MARCA Claro ha de ser contemplado por el público mexicano como algo suyo, nacido dentro de México, que es como ha sucedido, aunque también la parte española juegue un peso más decisivo que las versiones internacionales que estamos acostumbrados en otros proyectos".

\subsection{La expansión del proyecto a otros países latinoamericanos}

El desembarco de Marca en México es solo la punta de lanza de un proyecto de enorme calado, como es su expansión por Iberoamérica. Si el país norteamericano es el de mayor población del arco hispanohablante y en cierto modo por su localización geográfica la puerta de entrada al resto del continente, la continuidad de esta 
plataforma transnacional se producirá en otros dos países estratégicos en Sudamérica: Colombia y Brasil.

Colombia, con más de 48 millones de habitantes, es un mercado amplio, el segundo más importante de habla hispana tras México, donde el deporte, muy especialmente el fútbol, levanta grandes pasiones y, sin embargo, no existe una prensa especializada en deportes consolidada como ocurre en otros países del subcontinente. Hay, por tanto, un gran potencial para crecer en este país.

MARCA Claro se puso en marcha en Colombia en noviembre de 2017, y para ello adoptará la misma fórmula empleada en México, esto es, tener como socio al canal de televisión digital Claro Sports Colombia. Este canal, desde sus inicios en mayo de 2014, ha venido apostando por una programación no solo orientada al fútbol, sino también a otras disciplinas como son voleibol, bmx, squash, béisbol, ciclismo o tenis.

La web colombiana de MARCA Claro cuenta con una pequeña redacción local con periodistas (para ello se pensó en recuperar incluso a alguien que ya haya estado en Marca en España y de esa forma ayude a coordinar rutinas y procesos editoriales) y con un equipo de trabajo en la redacción en Madrid. De esta forma, se amplió a cuatro personas la redacción de MARCA Claro en España, que trabajan de forma autónoma, al igual que se está haciendo para México, de forma que cada sección tenga entidad propia dentro del proyecto.

Después de Colombia, el siguiente paso en el plan de expansión de
MARCA Claro será Brasil, un mercado gigantesco (unos 208 millones de habitantes) en el que ya importantes medios han abierto ediciones en lengua portuguesa, entre ellos The New York Times o El País, este último en 2013. Se trata de un mercado en el que Marca precisamente ya lo intentó hace un tiempo. Concretamente, en el año 2009 empezó a publicarse aquí el diario en papel y con dos ediciones, una en Río de Janeiro y otra en Sao Paulo (atendiendo así a la dualidad de los dos grandes campeonatos futbolísticos del país). Sin embargo, no le fue bien y tuvo que cerrar en 2012.

A pesar de tratarse de un mercado donde se habla otro idioma, en Brasil también se identifican las dos mismas claves que en México y Colombia para emprender la tercera etapa del proyecto MARCA Claro: por un lado, la existencia de un enorme potencial en un país donde hay una gran pasión por el fútbol y resto de deportes, y, sin embargo, solo hay un diario deportivo (Lance), por lo que se abren opciones para competir y lograr una importante audiencia; por otro, Claro TV también está muy implantada en este mercado (se puso en marcha en 2012), donde se comporta como un canal de suscripción vía satélite, y como compañía telefónica presta servicios digitales de roaming para voz y datos a más de 2.000 ciudades en este país.

\section{Conclusiones y discusión}

La internacionalización de Marca forma parte de una estrategia de expansión centrada en el Digital First y 
puede considerarse como la piedra angular para la supervivencia y crecimiento del liderazgo de este medio deportivo en los próximos años, así como una vía clave para fortalecer su viabilidad económica en unos tiempos complejos de cambio que afectan al conjunto de la industria periodística.

Se trata de un proceso que mira a Latinoamérica como una suma de mercados que, sobre todo por el idioma en su mayor parte pero también por el seguimiento que ahí se tiene del deporte español y por los deportistas de esos países que compiten en Europa, pueden impulsar de forma importante el crecimiento de Marca en audiencia y, con ello, en la cuenta de resultados.

El proyecto MARCA Claro, iniciado en México y que tendrá su continuidad en Colombia, se basa en la alianza con el grupo Carso (Claro Sports TV), que está implantado en todo el continente como compañía telefónica y que cuenta con importantes derechos de emisión, lo que abre grandes posibilidades al proyecto teniendo en cuenta la tendencia creciente al consumo de la información en formatos audiovisuales.

Además, Claro se constituye como el socio local con el que trabajar en una doble línea estratégica: crear un medio que apueste por la diferenciación a nivel nacional pero al mismo tiempo tener proyección global bajo el sello editorial de un diario deportivo de reconocido prestigio. La suma de lo local y lo internacional crea, además, sinergias a partir de dos redacciones en permanente coordinación, una en Madrid y otra en cada país donde se implante.

Las conclusiones de esta investigación, si bien parten de la limitación que supone circunscribirse a un caso de estudio en concreto, abren nuevas posibilidades para estudios futuros como el fenómeno de la internacionalización de los medios periodísticos en la actualidad y sus posibles ramificaciones tanto desde el punto de vista del negocio empresarial como de los contenidos y las audiencias.

\section{Bibliografía}

Boyle, R. (2006). Sports Journalism: Context and Issues. Londres: Sage.

Breiner, J. (2013). Emprendimientos periodísticos. Revista Mexicana de Comunicación, n. 133 (enero-marzo). Universidad Autónoma Metropolitana (UAM), pp. 34-39. Recuperado de: http://mexicanadecomunicacion.com.mx/rmc/2013/04/29/emprendimientos-periodisticos/ Brunner, S. y Horky, T. (2017). La prensa deportiva, una tipología periodística bajo presión. En Rojas Torrijos, José Luis (2017). Periodismo deportivo de manual. Valencia: Tirant Humanidades, pp. 31-58.

Casero Ripollés, A. (2012). Más allá de los diarios: el consumo de noticias de los jóvenes en la era digital. Comunicar, vol. 20 (39), pp. 151-158. https://doi.org/10.3916/C39-2012-03-05 Frujak, H; Frawley, H. y Bush, S. (2017). Quantifying the value of sport broadcast rights. Media International Australia, 9 de marzo. https://doi.org/10.1177/1329878X17698051 Miller, T. (ed.) (2001). Globalization and sport: Playing the world. Londres: Sage. Rojas Torrijos, J. L. (2011). Periodismo deportivo de calidad. Madrid: Fragua. 
Rojas Torrijos, J. L. (2015). Nuevos horizontes en el periodismo deportivo español: las primeras revistas para tabletas y móviles en los diarios Marca y Sport. Revista Fonseca, Journal of Communication, n. 10. Universidad de Salamanca, pp. 29-49. Recuperado de: http://revistas.usal.es/index.php/2172-9077/article/view/12910

Rowe, D. (2003). Sport, Culture $\Xi^{\circ}$ Media: The Unruly Trinity. Londres: McGraw-Hill Education. Túñez, M. et al. (2010). Nuevos entornos, nuevas demandas, nuevos periodistas. Estudios del Mensaje Periodístico, n. 16. Universidad Complutense de Madrid, pp. 79-94. Recuperado de: https://revistas.ucm.es/index.php/ESMP/article/viewFile/ESMP1010110079A/11358 